\title{
Investigation of noncovalent interactions between hydroxylated polybrominated diphenyl ethers and bovine serum albumin using electrospray ionization-ion mobility-mass spectrometry
}

\author{
Qiang Ma ${ }^{\mathrm{a}, \mathrm{b}, *}$, Hua Bai ${ }^{\mathrm{a}}$, Chao Wang ${ }^{\mathrm{a}}$, Guang-Cheng Xi ${ }^{\mathrm{a}}$, Qing Zhang ${ }^{\mathrm{a}}$, \\ Xian-Shuang Meng ${ }^{\mathrm{a}}$, Yun-Xia Chen ${ }^{\mathrm{a}}$, Jing-Rui $\mathrm{Li}^{\mathrm{a}}$, Hui-Juan Ma ${ }^{\mathrm{a}}$, Liang-Hong Guo ${ }^{\mathrm{b}, *}$ \\ a Chinese Academy of Inspection and Quarantine, Beijing 100123, China \\ ${ }^{\mathrm{b}}$ State Key Laboratory of Environmental Chemistry and Ecotoxicology, Research Center for Eco-Environmental Sciences, Chinese Academy of Sciences, \\ Beijing 100085, China
}

\section{A R T I C L E I N F O}

\section{Article history:}

Received 10 August 2013

Received in revised form 16 October 2013

Accepted 16 October 2013

Available online 25 October 2013

\section{Keywords:}

Hydroxylated polybrominated diphenyl ethers

Bovine serum albumin

Noncovalent interaction

Electrospray ionization

Ion mobility-mass spectrometry

\begin{abstract}
A B S T R A C T
The noncovalent interactions of 24 diversely structured hydroxylated polybrominated diphenyl ethers (OH-PBDEs), ranging from hydroxylated monobromodiphenyl ether (OH-monoBDE) to hydroxylated octabromodiphenyl ether (OH-octaBDE), with bovine serum albumin (BSA) have been examined by employing an electrospray ionization source fitted on a quadrupole time-of-flight hybrid mass spectrometer equipped with a traveling wave ion mobility cell. The mass spectrometric parameters were finely optimized to favor the observation of noncovalent complexes. The experimental data confirm that due to the close structural resemblance with thyroid hormone thyroxine, some OH-PBDEs have been shown to conjugate with BSA. It is found that BSA preferentially interacts with one $\mathrm{OH}$-octaBDE (4'-OHBDE-201) and two hydroxylated heptabromodiphenyl ether (OH-heptaBDE) isomers (4-OH-BDE-187 and 6-OH-BDE-180) with 1:1 and 2:1 binding stoichiometries. The state of bound OH-PBDEs is inferred to be as both neutral and anionic species. The dissociation constants of corresponding noncovalent complexes are calculated by titration curve data fitting. Investigation into various $\mathrm{OH}-\mathrm{PBDE}$ analogs demonstrates that both the degree of bromination and the positions of hydroxylation and bromine moieties may exert influence on the binding of OH-PBDEs to BSA. The possible conformational changes in BSA induced upon the binding of $\mathrm{OH}-\mathrm{PBDEs}$ were explored by use of ion mobility-mass spectrometry (IM-MS) to understand the details of the interactions in structural aspects.
\end{abstract}

(ㄷ) 2013 Elsevier B.V. All rights reserved.

\section{Introduction}

Polybrominated diphenyl ethers (PBDEs) are an important class of additive brominated flame retardants (BFRs), produced by brominating diphenyl ethers in the presence of catalysts, and are mainly applied to furniture foam, textile coatings, consumer electronics, wire and cable insulation, plastics for personal computers and small appliances, etc. [1,2]. These organohalogen compounds are intended to inhibit flame propagation by gas-phase radical quenching, thus reducing the spread of fire. Because of the widespread use, PBDEs have become ubiquitous environmental pollutants with their concentrations increasing very rapidly in the past 30 years, and have drawn great attention from ecological health and environmental perspectives. With the raising concern

\footnotetext{
* Corresponding authors at: Chinese Academy of Inspection and Quarantine, Beijing 100123, China. Tel.: +8610 85773279; fax: +861085772625.

E-mail addresses: maqiang@caiq.gov.cn(Q. Ma), LHGuo@rcees.ac.cn (L.-H. Guo).
}

about the potential hazard of PBDEs, hydroxylated polybrominated diphenyl ethers (OH-PBDEs), as their structural analogs, are emerging as a new group of chemicals that have attracted considerable interest due to various biological effects, including thyroid disturbance [3,4], neurotoxicity [5], cytotoxicity [6], and endocrine disruption $[7,8]$, etc. The occurrence of OH-PBDEs may originate from the anthropogenic formation via the uptake and metabolism of PBDEs or the accumulation of naturally existing compounds [9]. OH-PBDEs have been shown to bioconcentrate and bioaccumulate in abiotic environments [10-12] and organisms [13-15]. In particular, OH-PBDEs have been found in blood samples [16-21], with the detected concentrations escalating incrementally for the last few years [22,23].

The detection of OH-PBDEs in blood has generated questions about the relationship between OH-PBDEs blood level and their potential health effects. Although the toxicity of PBDEs is not fully understood, some of the toxic effects might be due to their hydroxylated metabolites, especially OH-PBDEs $[5,17]$. Several studies have confirmed that the in vivo exposure of experimental animals to 
PBDEs results in reduction of serum thyroid hormone level, indicating PBDEs exposure can exert adverse effects by interfering with the thyroid system [24-26]. There is growing evidence that the hydroxylation of PBDEs may further improve the effects of disturbing of the functioning of thyroid hormones [3]. Endogenous thyroid hormones, including thyroxine (T4) and its biologically active metabolite triiodothyronine (T3), are essential for the modulation of cellular metabolic pathways, the development and differentiation of several tissues, as well as energy homeostasis [27-30]. The environmental contaminants, to which organisms are routinely or involuntarily exposed, may disturb the thyroid system based on three mechanisms: (1) thyroid gland function and regulation; (2) thyroid hormone metabolism; and (3) thyroid hormone transport $[31,32]$. Thyroid hormones are produced in thyroid gland and then secreted into blood, where they are normally transported as noncovalent complexes with certain serum proteins and distributed to target tissues. The binding is known to occur with three main serum proteins: transthyretin (TTR), thyroxine-binding globulin (TBG) and serum albumin. Because of their structural similarity to thyroid hormones, both as hydroxylated and halogenated diphenyl ethers, OH-PBDEs may behave as competitive ligands for thyroid hormones transport proteins, thereby displacing thyroid hormones from serum proteins and altering the normal level of thyroid hormone in blood $[7,32,33]$. The end points of the disruption of thyroid hormone level are associated with abnormal thyroid function, long-lasting developmental deficits, and cancer [34]. It is therefore worthwhile to investigate the binding of OH-PBDEs with thyroid hormone transport proteins as an important mechanism of thyroid malfunction. The noncovalent interactions of $\mathrm{OH}-\mathrm{PBDEs}$ with the transport proteins TTR and TBG have been studied using several techniques, including fluorescence, circular dichroism, surface plasmon resonance, molecular docking, etc. [35-38]. However, the detailed interacting properties of OH-PBDEs with serum albumin have not been adequately explored yet. The binding of OH-PBDEs to serum albumin is of toxicological importance, since the normal distribution and metabolism of thyroid hormones would be affected. This motivates us to probe the potential interactions between $\mathrm{OH}$ PBDEs and serum albumin. Serum albumin, as the most abundant protein in the circulatory system of a wide variety of organisms, plays an important physiological role in the binding, transportation and delivery of various endogenous and exogenous compounds in blood [39-41]. In this work, bovine serum albumin (BSA) was selected as the serum albumin model, because of its abundance, availability, cost, and long-standing interest in protein community. Since their sequences are $76 \%$ conserved [42], results of this study can be extended to the human variant [43].

The success of electrospray ionization (ESI) started when Fenn $[44,45]$ showed that multiply charged ions were obtained from proteins by applying a strong electric field to a liquid passing through a capillary tube with a weak flux under atmospheric pressure. In recent years, electrospray ionization-mass spectrometry (ESIMS) has been acting as an important and fast-developing tool in research of noncovalent complexes with the advantages of speed, sensitivity, specificity and low sample consumption over other techniques [46-48]. The mild ionization procedure permits noncovalent conjugates to sufficiently retain their structural integrity upon the transition from solution state into gas phase $[49,50]$. Furthermore, ESI-MS can provide straightforward evidence for complex formation and accurate determination of their binding stoichiometries by measurement of molecular masses of all forms in the complexes.

Conformational flexibility of proteins plays a crucial role in molecular recognition and binding, and has been considered one of the most fundamental processes in biochemistry. According to the well-known induced-fit concept suggested by Koshland [51], the binding event may cause proteins to alter their local environment of the active sites to adapt to a guest molecule. However, allosteric protein structures remain a tough challenge to characterize. Evidencing subtle conformational transitions in proteins occurring upon small modulator binding usually requires atomic resolution techniques, such as X-ray crystallography (XRC), nuclear magnetic resonance (NMR), etc. [52]. Limitations of these techniques include: (1) a substantial amount of highly purified sample needed for NMR; (2) high financial costs; (3) lengthy time requirements; and (4) difficulty in obtaining good quality crystals for XRC. More recently, ion mobility-mass spectrometry (IM-MS) has emerged on the forefront of the structural characterization for biomolecular assemblies, and has been used in the investigation of protein conformations in gas phase [53,54]. IM-MS is a unique gas-phase electrophoretic technique that allows ionized target molecules to be separated on the basis of their mobility in the presence of an inert carrier gas and a weak electric field $[55,56]$. Several groups have reported that conformations in gas phase are consistent with measurement made using solution and/or solid structures [57-60]. Specifically, traveling-wave IMMS became popular with the introduction of a traveling-wave drift cell with ion mobility separation capability, replacing traditional ion mobility drift tube. This device employs traveling-wave technology in the cell composed of a stack of lenses. The cell acts as a radio frequency $(\mathrm{RF})$ ion guide to trap ions radially, similarly to an ion funnel but with constant lens inside diameter and without direct current (DC) component, with superimposed voltage waves traveling from lens to lens toward the exit of the lens stack. Following stacked ring ion guide geometry, ions are differentiated in a millisecond timescale based on their capacity to traverse through the ion mobility cell under the influence of repeating pulsed voltages [61]. Information on size, shape and charge states of proteins can be derived from measurement of their drift times, i.e., a parameter reflecting the gas-phase migration behavior in the buffer gas environment, therefore allowing the conformational changes in proteins linked to the binding of ligands to be revealed [62-64].

In this study, the interactions between BSA and 24 commercially available $\mathrm{OH}-\mathrm{PBDEs}$ with diverse structures, ranging from hydroxylated monobromodiphenyl ether (OH-monoBDE) to hydroxylated octabromodiphenyl ether (OH-octaBDE) were investigated by employing an ESI source fitted on a quadrupole time-of-flight mass spectrometer equipped with a traveling wave ion mobility cell. The purpose of the present work is to characterize the noncovalent binding of OH-PBDEs to BSA, and to evaluate the influence of structural features on their serum albumin binding properties. The possible ligand-provoked conformational transitions in BSA arising from the binding of OH-PBDEs were explored by use of the gas-phase ion mobility approach.

\section{Experimental}

\subsection{Materials}

Fatty acid and globulin free BSA with the purity of 99\% was purchased from Roche (Penzberg, Germany). Authentic OH-PBDE reference standards, all dissolved in acetonitrile with the concentrations of 10 or $50 \mu \mathrm{g} / \mathrm{mL}$, were obtained from AccuStandard (New Haven, CT, USA). The nomenclature for the OH-PBDEs in this paper follows the U.S. Environmental Protection Agency (EPA) numbering approach to simplify comparison with corresponding PBDE congeners [65]. The $24 \mathrm{OH}-\mathrm{PBDE}$ homologues involved in this study are listed in Table 1 and their chemical structures are shown in Fig. 1. Chemical reagents (formic acid, ammonium bicarbonate, etc.) were supplied to the highest purity grade by Sigma-Aldrich (St. Louis, MO, USA). 
Table 1

Information on the $24 \mathrm{OH}-\mathrm{PBDEs}$ investigated in this study.

\begin{tabular}{|c|c|c|c|}
\hline OH-PBDE Species & Compound & Abbreviation & Molecular Fourmula \\
\hline Hydroxylated monobromodiphenyl ether (OH-monoBDE) & 2'-Hydroxy-4-monobromodiphenyl ether & $2^{\prime}-\mathrm{OH}-\mathrm{BDE}-3$ & $\mathrm{C}_{12} \mathrm{H}_{9} \mathrm{O}_{2} \mathrm{Br}$ \\
\hline Hydroxylated dibromodiphenyl ether (OH-diBDE) & 3'-Hydroxy-2,4-dibromodiphenyl ether & 3'-OH-BDE-7 & $\mathrm{C}_{12} \mathrm{H}_{8} \mathrm{O}_{2} \mathrm{Br}_{2}$ \\
\hline \multirow[t]{3}{*}{ Hydroxylated tribromodiphenyl ether (OH-triBDE) } & 4'-Hydroxy-2,2',4-tribromodiphenyl ether & $4^{\prime}-\mathrm{OH}-\mathrm{BDE}-17$ & \multirow[t]{3}{*}{$\mathrm{C}_{12} \mathrm{H}_{7} \mathrm{O}_{2} \mathrm{Br}_{3}$} \\
\hline & 3'-Hydroxy-2,4,4'-tribromodiphenyl ether & $3^{\prime}-\mathrm{OH}-\mathrm{BDE}-28$ & \\
\hline & $2^{\prime}$-Hydroxy-2,4,4'-tribromodiphenyl ether & $2^{\prime}-\mathrm{OH}-\mathrm{BDE}-28$ & \\
\hline \multirow[t]{5}{*}{ Hydroxylated tetrabromodiphenyl ether (OH-tetraBDE) } & 4-Hydroxy-2,2',3,4'-tetrabromodiphenyl ether & 4-OH-BDE-42 & \multirow[t]{5}{*}{$\mathrm{C}_{12} \mathrm{H}_{6} \mathrm{O}_{2} \mathrm{Br}_{4}$} \\
\hline & 3-Hydroxy-2,2',4,4'-tetrabromodiphenyl ether & 3-OH-BDE-47 & \\
\hline & $4^{\prime}$-Hydroxy-2,2',4,5'-tetrabromodiphenyl ether & $4^{\prime}-\mathrm{OH}-\mathrm{BDE}-49$ & \\
\hline & 6-Hydroxy-2,2',4,4'-tetrabromodiphenyl ether & $6-\mathrm{OH}-\mathrm{BDE}-47$ & \\
\hline & $2^{\prime}$-Hydroxy-2,3',4,5'-tetrabromodiphenyl ether & $2^{\prime}-\mathrm{OH}-\mathrm{BDE}-68$ & \\
\hline \multirow[t]{6}{*}{ Hydroxylated pentabromodiphenyl ether (OH-pentaBDE) } & 3-Hydroxy-2,2',4,4',6-pentabromodiphenyl ether & 3-OH-BDE-100 & \multirow[t]{6}{*}{$\mathrm{C}_{12} \mathrm{H}_{5} \mathrm{O}_{2} \mathrm{Br}_{5}$} \\
\hline & 6-Hydroxy-2,2',3,3',4-pentabromodiphenyl ether & $6-\mathrm{OH}-\mathrm{BDE}-82$ & \\
\hline & 4-Hydroxy-2,2',3,4',5-pentabromodiphenyl ether & 4-OH-BDE-90 & \\
\hline & $4^{\prime}$-Hydroxy-2,2',4,5,5'-pentabromodiphenyl ether & $4^{\prime}-\mathrm{OH}-\mathrm{BDE}-101$ & \\
\hline & $5^{\prime}$-Hydroxy-2,2',4,4',5-pentabromodiphenyl ether & 5'-OH-BDE-99 & \\
\hline & $6^{\prime}$-Hydroxy-2,2',4,4',5-pentabromodiphenyl ether & $6^{\prime}-\mathrm{OH}-\mathrm{BDE}-99$ & \\
\hline \multirow[t]{3}{*}{ Hydroxylated hexabromodiphenyl ether (OH-hexaBDE) } & 6 -Hydroxy-2,2',3,4,4',5-hexabromodiphenyl ether & 6-OH-BDE-137 & \multirow{3}{*}{$\mathrm{C}_{12} \mathrm{H}_{4} \mathrm{O}_{2} \mathrm{Br}_{6}$} \\
\hline & 3-Hydroxy-2,2', $4,4^{\prime}, 5^{\prime}, 6$-hexabromodiphenyl ether & $3^{\prime}-\mathrm{OH}-\mathrm{BDE}-154$ & \\
\hline & 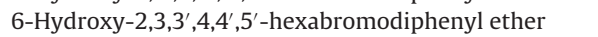 & 6-OH-BDE-157 & \\
\hline \multirow[t]{4}{*}{ Hydroxylated heptabromodiphenyl ether (OH-heptaBDE) } & 4-Hydroxy-2, $2^{\prime}, 3,4^{\prime}, 5,5^{\prime}, 6$-heptabromodiphenyl ether & 4-OH-BDE-187 & \multirow[t]{4}{*}{$\mathrm{C}_{12} \mathrm{H}_{3} \mathrm{O}_{2} \mathrm{Br}_{7}$} \\
\hline & 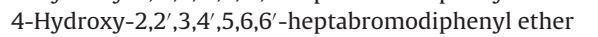 & 4-OH-BDE-188 & \\
\hline & 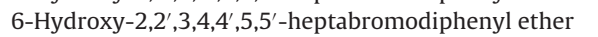 & $6-\mathrm{OH}-\mathrm{BDE}-180$ & \\
\hline & 6-Hydroxy-2,2',3,4,4',5,6'-heptabromodiphenyl ether & 6-OH-BDE-182 & \\
\hline Hydroxylated octabromodiphenyl ether (OH-octaBDE) & $4^{\prime}$-Hydroxy-2, $2^{\prime}, 3,3^{\prime}, 4,5^{\prime}, 6,6^{\prime}$-octabromodiphenyl ether & $4^{\prime}-\mathrm{OH}-\mathrm{BDE}-201$ & $\mathrm{C}_{12} \mathrm{H}_{2} \mathrm{O}_{2} \mathrm{Br}_{8}$ \\
\hline
\end{tabular}

\subsection{Preparation of the noncovalent complexes of $\mathrm{OH}-\mathrm{PBDEs}$ and} $B S A$

An aqueous stock solution of native BSA was prepared with Milli-Q ultrapure water (Millipore, Bedford, MA, USA) to yield a $10 \mathrm{mM}$ solution. Molecular weight of $66 \mathrm{kDa}$ was used to calculate the molar concentration for BSA. The BSA stock solution was then desalted making use of an Amicon Ultra-15 centrifugal filter unit with an Ultracel-10 membrane of $10 \mathrm{kDa}$ molecular weight cutoff (Millipore, Bedford, MA, USA) to remove nonvolatile salts (sodium, potassium, calcium, magnesium salts, etc.) contained in the lyophilized BSA powder and prevent interference with downstream processes. The concentrate was subsequently buffer exchanged against $20 \mathrm{mM}$ fresh ammonium bicarbonate solution<smiles>Oc1ccccc1Oc1ccc(I)cc1</smiles>

2'-OH-BDE-3 (1)<smiles>Cc1ccc(Oc2ccc(O)c(Br)c2[18O])c(C)c1</smiles><smiles>[Ge]O[Pb]</smiles><smiles>[2H]c1cc(C)c(Oc2ccc(C)cc2Br)c([18O])c1O</smiles>

3-OH-BDE-100 (11)<smiles>Oc1cc(Br)cc(Br)c1Oc1cc(Br)cc(Br)c1O</smiles>

6'-OH-BDE-99 (16)

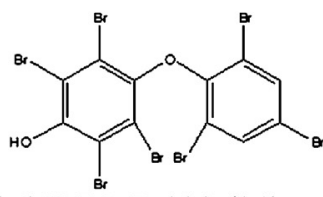

4-OH-BDE-188 (21)<smiles>Cc1ccc(Oc2cccc(O)c2)c(C)c1</smiles>

3'-OH-BDE-7 (2)<smiles>[2H]c1ccc(Oc2ccc(Br)c(O)c2[18O])c(Br)c1</smiles>

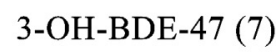<smiles>[2H]c1cc(O)c(Oc2cccc(C)c2[18O])c([18F])c1Br</smiles>

6-OH-BDE-82 (12)

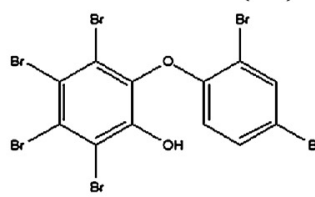

6-OH-BDE-137 (17)

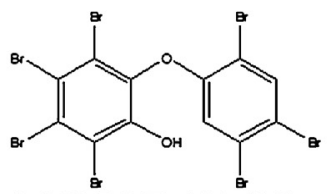

6-OH-BDE-180(22)<smiles>Oc1ccc(Oc2ccc(Br)cc2Br)c(Br)c1</smiles>

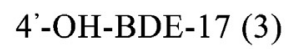<smiles>Oc1cc(Br)c(Oc2ccc(Br)cc2Br)cc1Br</smiles><smiles>[10BH2]O[13CH3]</smiles><smiles>Oc1cc(Oc2ccc(Br)cc2[18F])ccc1I</smiles><smiles>Cc1ccc(Oc2ccc(I)cc2C)c(O)c1</smiles><smiles></smiles>

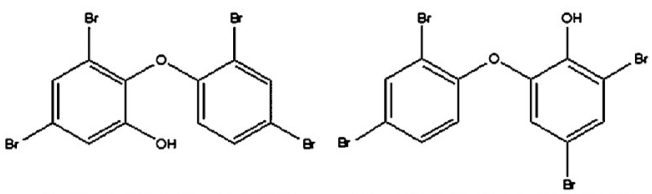<smiles>[CH2]O[Pb]</smiles><smiles>[18O][18O][18O]</smiles><smiles>[Z]O[Pb][Ba]</smiles><smiles>Cc1cc(Oc2ccc(Br)cc2Br)c(Br)c(Br)c1O</smiles>

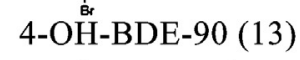

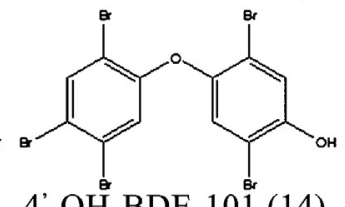

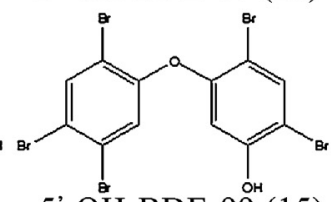<smiles>[2H]c1cc(Br)c(Br)c(Br)c1Oc1cc(O)c(Br)cc1Br</smiles><smiles>[BH3-]O[GeH3]</smiles><smiles></smiles>

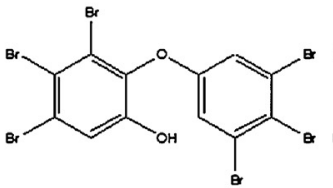

3'-OH-BDE-154 (18)<smiles>[2H]c1c(Br)c(O)c(Br)c([2H])c1Oc1cc(I)c(C)cc1Br</smiles>

4-OH-BDE-187 (20)

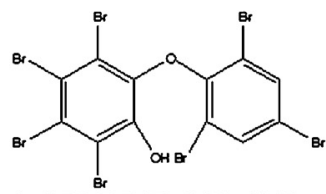

6-OH-BDE-157 (19)

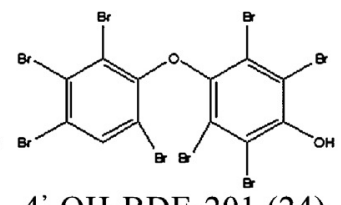

4'-OH-BDE-201 (24)

Fig. 1. Chemical structures of the $24 \mathrm{OH}-\mathrm{PBDEs}$ investigated in this study. 
at $\mathrm{pH}$ 7.4, with $\mathrm{pH}$ adjusted using aqueous formic acid solution. The noncovalent complexations of BSA with OH-PBDEs were evaluated by individually preparing the reaction mixtures of BSA with $24 \mathrm{OH}-\mathrm{PBDE}$ congeners prior to instrumental analyses. $100 \mu \mathrm{L}$ of constant concentration of BSA $(15 \mu \mathrm{M})$ was titrated with increasing volumes of each $\mathrm{OH}-\mathrm{PBDEs}$ to obtain five different complex concentrations in the range of ligand to protein molar ratios from 0.3 to 3.0, and then diluted to a final volume of $1 \mathrm{~mL}$ with $20 \mathrm{mM}$ ammonium bicarbonate buffer. The mixed solutions of BSA and OH-PBDEs were incubated at room temperature for $30 \mathrm{~min}$ to reach equilibrium and continuously infused into the mass spectrometer via an integrated syringe pump at a flow rate of $10 \mu \mathrm{L} / \mathrm{min}$ for cumulation of $3 \mathrm{~min}$.

\subsection{ESI-MS measurement}

ESI-MS studies were performed on a SYNAPT HDMS hybrid quadrupole ion mobility orthogonal acceleration time-of-flight mass spectrometer (Waters, Manchester, UK) equipped with a Zspray source, an electrospray probe and a build-in syringe pump. The traveling wave ion mobility function was manually inactivated at this stage. The instrument was operated in electrospray positive-ion mode with a capillary voltage of $3.0 \mathrm{kV}$ and a nitrogen desolvation gas flow rate of $400 \mathrm{~L} / \mathrm{h}$ at a temperature of $40^{\circ} \mathrm{C}$. The source temperature was kept at $30^{\circ} \mathrm{C}$. A sampling cone voltage of $42 \mathrm{~V}$ and an extraction cone voltage of $1.0 \mathrm{~V}$ were set for the experiment. The quadrupole mass filter was run in the wide-band pass-through mode. The ions were subsequently accumulated into an ion guide region at the pressure of 0.01 mbar with a trap collision energy set at $40 \mathrm{eV}$, an argon trap gas flow rate of $1.5 \mathrm{~mL} / \mathrm{min}$, and a transfer collision energy at $0.0 \mathrm{eV}$. Mass spectra were recorded by a reflectron time-of-flight (TOF) mass analyzer operating in V-Optics mode over the range of $m / z 100-5500$, with the repeated 2.0-s scan time and $0.02-s$ inter-scan interval. The resulting positive-ion mass spectra were produced by averaging $3 \mathrm{~min}$ of accumulative data to attain good signal-to-noise ratio. The TOF mass analyzer was externally calibrated with a $\left[\mathrm{Glu}^{1}\right]$ Fibrinopeptide B solution at the concentration of $100 \mathrm{fmol} / \mu \mathrm{L}$ in $50 \%(\mathrm{v} / \mathrm{v})$ aqueous acetonitrile acidified with $0.1 \%(\mathrm{v} / \mathrm{v})$ formic acid. All analyses were acquired utilizing an independent LockSpray reference sprayer infusing $200 \mathrm{ng} / \mathrm{mL}$ protonated leucine enkephalin solution $(\mathrm{m} / \mathrm{z}$ 556.2771 ) at a flow rate of $5 \mu \mathrm{L} / \mathrm{min}$ to verify mass accuracy. Instrumentation control, data acquisition and mining were carried out by MassLynx version 4.1 software supplied with the instrument (Waters, Manchester, UK).

\subsection{IM-MS analysis}

IM-MS experiment was conducted on the same SYNAPT HDMS mass spectrometer (Waters, Manchester, UK) with the traveling wave ion mobility device in use. Most mass spectrometric parameters remained the same as in the ESI-MS measurement. The ion mobility cell is part of the interaction region that comprises of three traveling wave ion guides with geometry of trap T-Wave, IM TWave, and transfer T-Wave. Both trap and transfer ion guides were operated at the pressure of 0.02 mbar supplied by a $1.5 \mathrm{~mL} / \mathrm{min}$ argon gas flow. The analyte ions were pulsed into the ion mobility drift cell over a period of $128 \mu$ s to undertake an ion mobilitybased separation at the pressure of 0.38 mbar supplied by a nitrogen IM-MS gas flow rate of $15 \mathrm{~mL} / \mathrm{min}$. Each individual ion mobility experiment was $25.64 \mathrm{~ms}$ long with a $300 \mathrm{~m} / \mathrm{s}$ traveling wave at the amplitude of $8.0 \mathrm{~V}$. The ions passing through the drift cell were then continually released to a transfer ion guide region with a transfer collision energy set at $12 \mathrm{eV}$. Finally, the mobility-separated ions were conveyed to the reflectron TOF mass analyzer operating in $\mathrm{V}$-Optics mode whilst maintaining the temporal separation.

\section{Results and discussion}

\subsection{Optimization of parameters for noncovalent complexations between $\mathrm{OH}$-PBDEs and BSA}

Since its introduction, ESI-MS has served as a powerful analytical tool in providing evidence in support of the formation of noncovalently associated complexes. It should be noted that gentle mass spectrometric conditions are required so that noncovalent interactions survive the ionization and desorption processes when ions are transferred from condensed phase to gas phase. The acquisition settings were carefully tuned in order to preserve the integrity of noncovalent assembly without compromising ion desolvation and transmission efficiency. The source temperature as well as desolvation gas temperature was found to be critical for the complexations of OH-PBDEs with BSA. Low temperature was employed to favor conserving the intact $\mathrm{OH}-\mathrm{PBDEs} / \mathrm{BSA}$ complexes in gas phase. As the sampling cone voltage was varied from 10 to $100 \mathrm{~V}$, the resulting mass spectrometric sensitivity increased with the increasing of the voltage. However, in-source fragmentation occurred when the voltage was at the value in excess of $45 \mathrm{~V}$. The optimal sampling cone voltage was achieved at $42 \mathrm{~V}$, giving good sensitivity while preventing the OH-PBDEs/BSA complexes from fragmentation. The trap collision energy, i.e., the potential applied at which ions entered the trap cell, is another parameter demonstrating a major impact on the binding of OH-PBDEs to BSA. An appropriate voltage is required for the transmission of high mass ions, and on the other hand, without provoking dissociation of the complexes. A compromise between optimal transmission of the ions and nondestructive gas-phase collisions was found at $40 \mathrm{~V}$. The capillary voltage also exerted influence on the intensity of the adduct peaks, and it was optimized to be $3.0 \mathrm{kV}$. With the above parameters, optimum sensitivity was obtained while the noncovalent complexes remained intact.

\subsection{Mass spectra of BSA and OH-PBDEs/BSA complexes}

The experimental results demonstrated that individual $\mathrm{OH}-$ PBDE congeners gave dominant deprotonated molecule $[\mathrm{M}-\mathrm{H}]^{-}$in electrospray negative-ion mode. The presence of differing numbers of bromines was manifested by the characteristic isotopic clusters patterns as well as their relative abundance ratios (data not shown), which matched well with the theoretical mass spectra simulated by an "isotope modeling" computing module embedded in the MassLynx software. As illustrated in Fig. 2a, under gentle electrospray conditions, BSA generated an envelope of protonated multiply charged ions in positive-ion mode showing a visible charge-state distribution from $14+$ to $18+$. The abundance of different ion peaks was detected to be charge state dependent. With the mass spectrometric parameters applied, $[\mathrm{M}+16 \mathrm{H}]^{16+}$ appeared most abundantly. An average molecular mass of $(66,598 \pm 10 \mathrm{Da})$ was derived for BSA upon deconvolution of the mass spectra using the MaxEnt algorithm of the MassLynx software, which is in good agreement with its theoretical value, less than $1 \%$ mass difference. The $\mathrm{pH}$ of liquidphase solution was relating to the conformational state of BSA, hence demonstrated influence on its post-ionization charge-state distribution. If the $\mathrm{pH}$ value was less than 4.0 , a broad charge-state distribution of denatured BSA was observed, shifting the signals to lower $\mathrm{m} / \mathrm{z}$ from 800 to 2000 (data not shown), since denatured BSA molecule exposes more sites for protonation. On the other hand, a charge-state distribution at higher mass range of $m / z$ 3600-5000 (Fig. 2a) corresponds to non-denaturing BSA. A buffer solution at a physiological $\mathrm{pH}$ of 7.4 was found to give good response while maintaining the native conformation of BSA.

In the present work, the noncovalent interactions of all commercial OH-PBDE analogs currently available, ranging from 


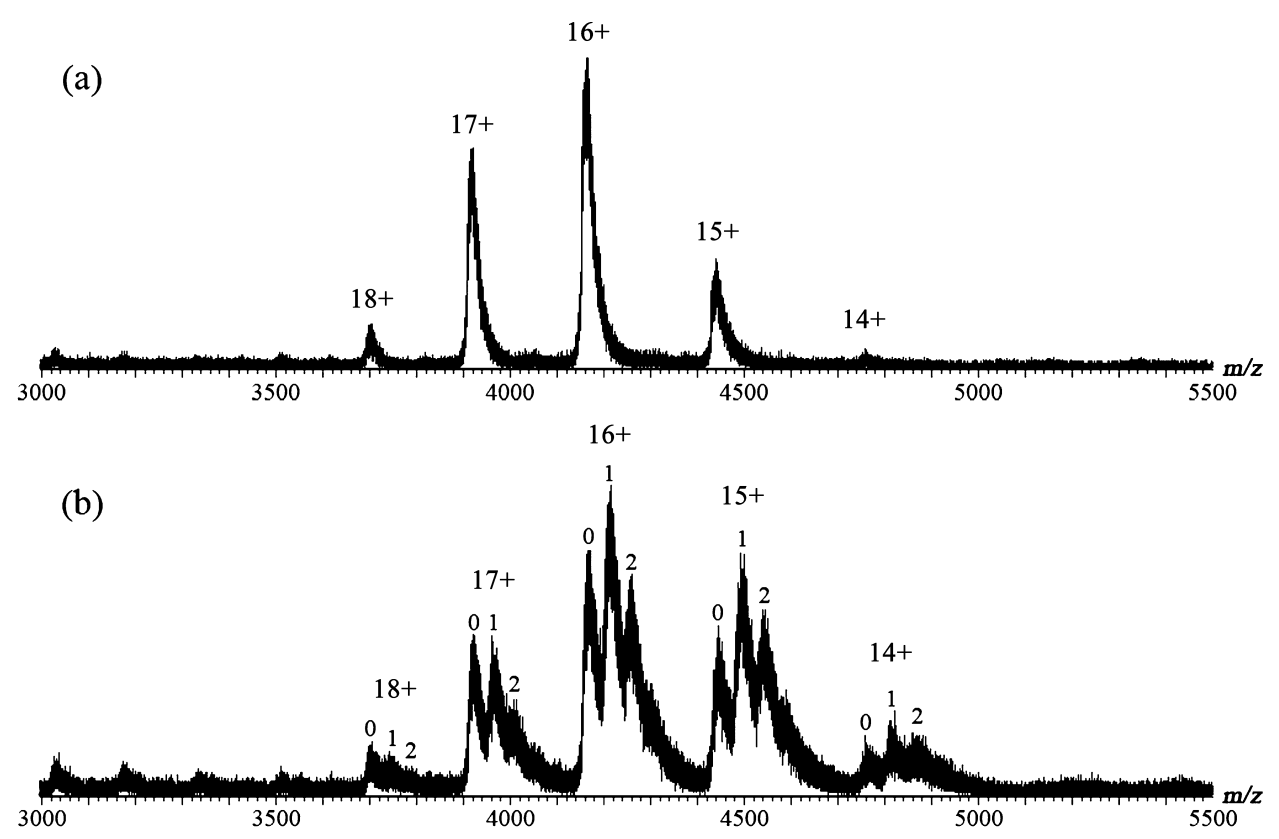

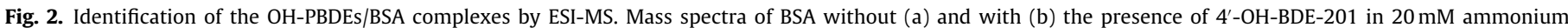

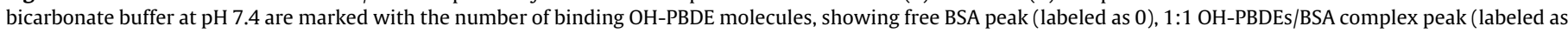
1), and 2:1 OH-PBDEs/BSA complex peak (labeled as 2).

OH-monoBDE to OH-octaBDE, with BSA were studied by ESI-MS. There are sub-series of isomeric species within certain $\mathrm{OH}-$ PBDE groups, specifically, three hydroxylated tribromodiphenyl ether $(\mathrm{OH}$-triBDE) isomers, five hydroxylated tetrabromodiphenyl ether (OH-tetraBDE) isomers, six isomers within hydroxylated pentabromodiphenyl ethers (OH-pentaBDEs), three isomers within hydroxylated hexabromodiphenyl ethers (OH-hexaBDEs), and four hydroxylated heptabromodiphenyl ether (OH-heptaBDE) isomers. The structural isomers distinguish from each other by the bromine substitution sites as well as the placement of single hydroxyl group, i.e., the location in the ortho-, meta-, or para-position relative to the diphenyl ether bridge. Unlike most spectroscopic methods, ESI-MS provides a fast and direct way to characterize the binding stoichiometries of noncovalent complexes. Meanwhile, mass spectrometer, as a multichannel detector, enables all analytes in the reaction mixture to be differentiated simultaneously. Among the $24 \mathrm{OH}-\mathrm{PBDEs}$ investigated, it was found that BSA interacted preferentially with one OH-octaBDE (4'-OH-BDE-201) and two $\mathrm{OH}$-heptaBDE isomers (4-OH-BDE-187 and 6-OH-BDE-180). Even though each individual instrumental parameters were adjusted very thoroughly, no complex peaks corresponding to BSA conjugated with other OH-PBDE congeners were detected, indicating no or quite weak interactions between those OH-PBDEs and BSA. The representative mass spectrum of the mixture of 4 '-OH-BDE201 and BSA, as shown in Fig. 2b, exemplifies the complexations of OH-PBDEs with BSA. Fig. $2 \mathrm{~b}$ reveals the occurrence of complexes between 4'-OH-BDE-201 and BSA of various stoichiometric relations. The $1: 1$ and 2:1 ratios of the OH-PBDEs/BSA complex peaks as well as the free BSA peak were clearly observed in the mass spectrum, distinguishing from each other. The binding of BSA with 4'-OH-BDE-201 led to approximate increases in mass by 809 and $1618 \mathrm{Da}$, respectively, which could be attributed to the formation of $1: 1$ and 2:1 complexes. Despite the molar excess of OH-PBDEs, a fraction of BSA remained in its native unbound state and a maximum of two OH-PBDE molecules were shown to bind per multiply-protonated molecule of BSA. For the peaks of charge state $17+$ and $18+$, the unbound BSA ion was the most intensive peak. The abundance of the $1: 1$ complex was slightly lower and a small amount of the 2:1 complex also appeared. For those ions carrying $14+, 15+$, and $16+$ electric charges, the $1: 1$ complex was the predominant species. The OH-PBDEs/BSA adducts ions of 2:1 stoichiometry and ligand-free BSA ions were less intensive. The phenomenon demonstrates that the capability of BSA to bind $\mathrm{OH}-$ PBDEs in gas phase may gradually weaken as charge increases. Another interesting aspect was that the charge-state distribution of BSA changed with the binding of 4'-OH-BDE-201. Although the $16+$ ions remained the most intense ions for both apo- and holoBSA, it was observed that the peak abundance of charge state 17+ was higher than that of charge state $15+$ in the absence of $4^{\prime}-\mathrm{OH}-$ BDE-201, while with the presence of $4^{\prime}-\mathrm{OH}-\mathrm{BDE}-201$, the relative peak abundance for the two charge-state series were in reverse order. The relative abundance of the pair of $18+$ and $14+$ charge states was also found to vary inversely with the binding of $4^{\prime}-\mathrm{OH}-$ BDE-201. The charge-state distribution in an electrospray spectrum has been shown to correlate with tertiary protein structure [66]. Similar binding stoichiometries of $1: 1$ and $2: 1$ ratios with BSA were observed for two OH-heptaBDEs (4-OH-BDE-187 and 6-OHBDE-180) (see Supplementary Materials, which can be found in the electronic version of this article, Figs. S1 and S2). The ESI-MS assay performed in this work confirms the noncovalent interactions of OH-PBDE congeners with BSA and further suggests that the binding is effectively transferred and sustained in gas phase under proper conditions. ESI-MS allows direct assignment of the binding stoichiometries that BSA can bind as many as two molecules of $\mathrm{OH}$ PBDEs. This observation agrees quite well with the fact that there are two major binding sites on serum albumin [67,68].

Mass spectrometry, as an advantageous technique for analyzing noncovalent interactions between proteins and ligands due to its ability to provide some indication of the state of the binding species, permits investigation of the OH-PBDEs bound with BSA as either a neutral or charged species. The binding of an anionic species normally causes a decrease in the net average charge distribution of the multiply-protonated protein in comparison to the charge distribution of the protein in the absence of such an anionic species. On the other hand, if the ligands bind to the protein as a neutral species, the formation of the complex will not change the charge state distribution of the protein. In view of the fact that the total degree of ionization or the number of charged species produced 
per second from the ESI capillary will remain constant for identical experimental conditions. Therefore, the binding of OH-PBDE molecules will not change the number of charged species generated per second compared with the number of BSA ions without $\mathrm{OH}$ PBDE ligands bound in the mass spectrum of BSA alone. To relate the total intensities before and after the addition of OH-PBDEs to $\mathrm{BSA}$, the peak intensities of the five charge states $14+$ to $18+$ for BSA alone (Fig. 2a) were summed to be 135.5 units, with the relative intensities of charge state $18+$ through to $14+$ for BSA alone of $8.5\left(18^{+}\right)$: $43.0(17+)$ : $60.5(16+)$ : $21.5\left(15^{+}\right)$: 2.0 (14+). Based on normalizing the mass spectrometric data, one finds that the distribution of charge state intensities for unbound BSA is $14.0(18+)$ : $71.1(17+)$ : $100.0(16+): 35.8(15+): 3.3(14+)$. Similarly, a total of 409.5 units was obtained by adding together the same five charge states of BSA plus 4'-OH-BDE-201 (Fig. 2b). It can be inferred from these values that the latter signals has been amplified by a factor of $409.5 / 135.5=3.02$. To compare the ion population of the five charge states in each of Fig. 2a and b, the ion intensity of the five charge states $14+$ to $18+$ in Fig. $2 \mathrm{~b}$ should be divided by the factor of 3.02 to be $7.6(18+)$ : $26.8(17+): 50.3(16+)$ : $38.2\left(15^{+}\right)$: $12.4(14+)$. Once more the distribution of charge state intensities was normalized as $15.1(18+)$ : $53.6(17+): 100.0(16+)$ : $76.0\left(15^{+}\right): 24.7(14+)$. It should be noted that there is a loss of ion intensity in the $18+, 17+$ and $16+$ charge states due to reaction of BSA with $4^{\prime}-\mathrm{OH}-\mathrm{BDE}-201$. Not only is there a gain of ion intensity in the $15+$ and $14+$ charge states due to reaction of BSA with $4^{\prime}-\mathrm{OH}-\mathrm{BDE}-201$, but the magnitude of the gains in the $15+$ and $14+$ charge states are equal to the losses in the $17+$ and $16+$ charge states, respectively. From these observations, if the one and two OH-PBDEs molecules have added to each charge state in a similar manner such that the number of charges on any charge state does not change due to the addition of such a molecule, then the distribution of charge state intensities, for BSA plus $\mathrm{OH}-$ PBDEs molecules, should be similar to that for BSA charge state alone. In this case, the ligand OH-PBDEs molecules can be proposed either as neutral species or as deprotonated molecules that cluster with BSA simultaneously with addition of a proton from solution so that the charge of the reactant charge state remains unchanged. Upon consideration of the relative charge state signal intensities for BSA alone and for BSA plus 4'-OH-BDE-201, particularly the magnitudes of the gains in the $15+$ and $14+$ charge states being equal to the magnitudes of the losses in the $17+$ and $16+$ charge states, respectively, the shift in the distribution of charge states before and after the attachment of $\mathrm{OH}-\mathrm{PBDEs}$ implies the fact that a fraction of OH-PBDEs add as anions to BSA, decreasing the charge state of the host, while a small fraction of OH-PBDEs add as neutral species to BSA, such that the charge state is unchanged. Thus there is a mixture of reactant molecules adding to BSA. We propose a model for the reaction of BSA with OH-PBDEs as follows:

$$
\begin{aligned}
& \mathrm{M}^{n+}+\mathrm{L} \rightarrow \mathrm{ML}^{n+} \\
& \mathrm{M}^{n+}+2 \mathrm{~L} \rightarrow \mathrm{ML}_{2}^{n+} \\
& \mathrm{M}^{n+}+\mathrm{L}^{-} \rightarrow \mathrm{ML}^{(n-1)+} \\
& \mathrm{M}^{n+}+2 \mathrm{~L}^{-} \rightarrow \mathrm{ML}^{(n-2)+}
\end{aligned}
$$

It is assumed that the maximum number of OH-PBDEs molecules forming ligands $(L)$ with a given BSA charge state is two. $\mathrm{M}^{n+}$ represents any one of the five charge states observed for BSA. Up to two deprotonated OH-PBDEs molecules $\left(\mathrm{L}^{-}\right)$may cluster with a BSA charge state. It is assumed further that Reactions (2) and (4) occur sufficiently rapidly that it is not necessary to invoke further reactions of $\mathrm{ML}^{n+}$ and $\mathrm{ML}^{(n-1)+}$ with $L$ and $L^{-}$, respectively. The procedure is to discuss the fates of each of the initial charge state intensities so as to arrive at the final experimental charge

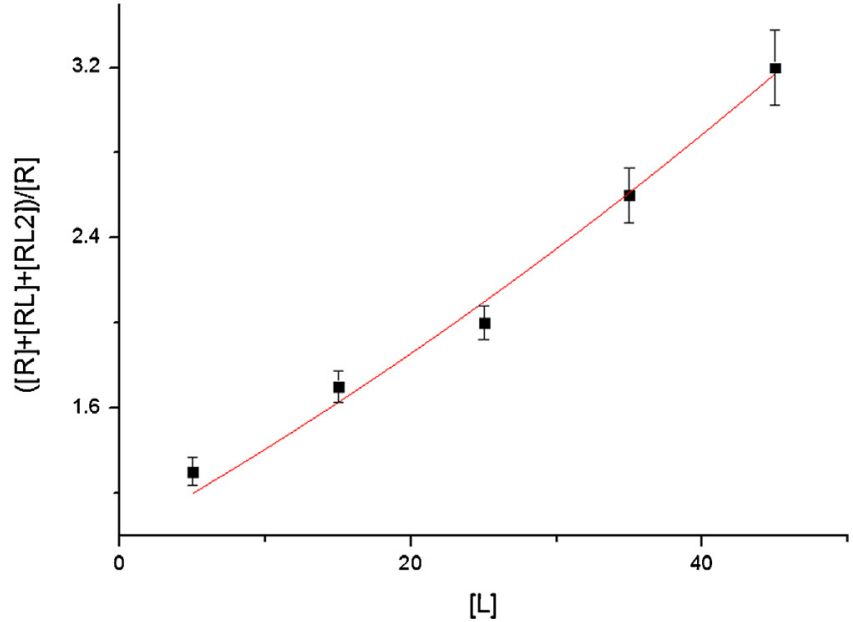

Fig. 3. Determination of dissociation constants of the noncovalent complex between 4'-OH-BDE-201 and BSA. The dissociation constants were calculated by holding the concentration of BSA at $15 \mu \mathrm{M}$ and titrating OH-PBDEs from 5 to $45 \mu \mathrm{M}$. A binomial fit gave an equation of $Y=2.17 \mathrm{E}^{-4} X^{2}+3.85 \mathrm{E}^{-2} X+1.00$ with the correlation coefficient of 0.9983 .

state intensities calculated for Fig. 2 b. Once the fates of all of the initial ion intensities have been proposed, it should be possible to determine the chemical processes equivalent to these fates. Hopefully, the chemical processes defined by the allocation of the initial charge state ion intensities will correspond to those in the model proposed above. In general, it is postulated that peaks $18_{1}{ }^{+}, 17_{1}{ }^{+}$, $16_{1}{ }^{+}$, and $15_{1}{ }^{+}$are formed by Reaction (1); peaks $18_{2}{ }^{+}, 17_{2}{ }^{+}, 16_{2}{ }^{+}$, and $15_{2}{ }^{+}$are formed by Reaction (2); peaks $17_{1}{ }^{+}, 16_{1}{ }^{+}$, and $15_{1}{ }^{+}$are formed also by Reaction (3); peak $14_{1}{ }^{+}$is formed only by Reaction (3); peaks $15_{2}{ }^{+}$and $14_{2}{ }^{+}$are formed by Reaction (4).

\subsection{Determination of dissociation constants for $O H-P B D E S / B S A$ complexes}

Based on characterization of the binding stoichiometries between $\mathrm{OH}-\mathrm{PBDEs}$ and BSA, the potential binding potency of $4^{\prime}$ OH-BDE-201, 4-OH-BDE-187 and 6-OH-BDE-180 with BSA was assessed quantitatively by determining the dissociation constants for the OH-PBDEs/BSA complexes. There are several solution-phase methods for the determination of the dissociation constants of noncovalent complexes. These methods are often laborious and may require large quantities of materials and typically measure only the equilibrium concentration of either the free ligand or the complex. Since little or no information pertaining to the binding stoichiometries of the complex can be provided, a single dissociation constant that is an average of multiple dissociation constants may actually be calculated [69]. In contrast, we calculate the dissociation constants by ESI-MS, which enables the detection of both free and bound forms of BSA simultaneously. Since OH-PBDE congeners are much smaller in molecular mass compared with BSA, and will not interfere significantly with the ionization processes on the surface of the protein. It is therefore assumed that the ionization efficiency remains the same for intact and bound BSA. Furthermore, this assumption allows us to measure the relative amounts of differing species in solution based on their respective peak intensity in the mass spectra. According to the reference [70], the dissociation constants $\left(K_{\mathrm{D}}\right)$ for the OH-PBDEs/BSA complexes were measured by fixing the concentration of BSA at $15 \mu \mathrm{M}$ and titrating OH-PBDEs from 5 to $45 \mu \mathrm{M}$. A plot of $\left([R]+[R L]+\left[R L_{2}\right]\right) /[R]$ versus $[L]$ yields a binomial curve (Fig. 3 ) using the following equation:

$\frac{[\mathrm{R}]+[\mathrm{RL}]+\left[\mathrm{RL}_{2}\right]}{[\mathrm{R}]}=\frac{[\mathrm{L}]^{2}}{K_{\mathrm{D} 1} K_{\mathrm{D} 2}}+\frac{[\mathrm{L}]}{K_{\mathrm{D} 1}+1}$ 
where $R$ represents free BSA, L stands for OH-PBDE congeners, $\mathrm{RL}$ is the 1:1 OH-PBDEs/BSA complex, and $\mathrm{RL}_{2}$ is the $2: 1$ complex. The $K_{\mathrm{D}}$ calculation and titration curve data fitting were performed with Origin version 8.0 software (OriginLab, Northampton, MA, USA). A binomial fit of the data gave a correlation coefficient of 0.9983 for the noncovalent complexes of BSA formed with one and two molecules of 4'-OH-BDE-201; $K_{\mathrm{D} 1}$ was calculated to be $26.0 \mu \mathrm{M}$ and $K_{\mathrm{D} 2}$ was $143.1 \mu \mathrm{M}$. Similarly, the $K_{\mathrm{D} 1}$ and $K_{\mathrm{D} 2}$ for the complexes between $4-\mathrm{OH}-\mathrm{BDE}-187$ and BSA were $33.9 \mu \mathrm{M}$ and $177.8 \mu \mathrm{M}$, respectively. For $6-\mathrm{OH}-$ BDE-180, the two values were individually calculated to be $49.1 \mu \mathrm{M}$ and 197.3 $\mu \mathrm{M}$. In general, the dissociation constants of OH-PBDEs with BSA were found to be within the range of the reported magnitude between $10^{-6} \mathrm{M}$ and $10^{-4} \mathrm{M}$ as other binding ligands [71].

Investigation of the binding potency of the $24 \mathrm{OH}-\mathrm{PBDE}$ homologues reveals some structural characteristics of the complexations between OH-PBDEs and BSA. The experimental data indicate that the binding affinity of OH-PBDE congeners for BSA is clearly associated with the degree of bromination. Highly brominated OH-PBDEs, such as $\mathrm{OH}$-octaBDE and $\mathrm{OH}$-heptaBDE, can form noncovalent complexes with BSA more easily than lower brominated OH-PBDEs. 4'-OH-BDE-201 showed the lowest dissociation constant and the highest binding potency for BSA. In addition to the effect of bromination, BSA binding affinity of OH-PBDEs was also found to be dependent on the position of hydroxyl group. OH-PBDEs with a hydroxyl group in the para-position have been shown to be a more potent ligand for BSA than those with a hydroxyl group in the ortho-position. The structural disparity between 4-OH-BDE187 and 6-OH-BDE-180 lies in an inverse distribution of $\mathrm{C} 4$ and C6 substitutions (C4 hydroxyl and C6 bromine for 4-OH-BDE-187, C4 bromine and C6 hydroxyl for 6-OH-BDE-180, respectively). 4-OH-BDE-187 could exhibit stronger affinity for BSA than 6-OHBDE-180 based on comparison of their dissociation constants. The positions of the bromine moieties are also identified as important factors in the binding interactions of OH-PBDEs with BSA. Among the four OH-heptaBDEs examined, 4-OH-BDE-187 and 6-OH-BDE-180 were found to interact with BSA, while 4-OH-BDE188 and 6-OH-BDE-182 did not show binding. It is noteworthy that 4-OH-BDE-187 and 4-OH-BDE-188 share the same level of bromination and same hydroxylation positions, but only differ in one bromine location ( $\mathrm{C}^{\prime}$ bromine for $4-\mathrm{OH}-\mathrm{BDE}-187$ and $\mathrm{C6}^{\prime}$ bromine for 4-OH-BDE-188, respectively). One possible explanation is that the adjacent $\mathrm{C} 6$ and $\mathrm{C}^{\prime}$ bromines of 4-OH-BDE-188 create much steric hindrance and twist the compound, which are unfavorable for fitting into the binding pockets of BSA, thus prevent 4-OH-BDE-188 from binding to BSA. Likewise, 6-OH-BDE-180 and 6-OH-BDE-182 possess the same bromine numbers and same hydroxyl group in the ortho-position, but with slight difference in the position of one bromine substitution ( $\mathrm{C}^{\prime}$ bromine for 6 OH-BDE-180 and C6' bromine for 6-OH-BDE-182, respectively). The same trend was observed that the steric hindrance originated from the adjacent $\mathrm{C} 6$ hydroxyl and $\mathrm{C}^{\prime}$ 'bromine might hamper the binding of 6-OH-BDE-182 to BSA. The comparison of $4^{\prime}-\mathrm{OH}-\mathrm{BDE}-$ 201 to $4-\mathrm{OH}-\mathrm{BDE}-188$ in structure reveals a minor difference, i.e., one more bromine substitution in the meta-position. BSA binding potency was indeed observed for 4'-OH-BDE-201, although structural steric hindrance may occur due to the adjacent $\mathrm{C} 6$ and C6 $^{\prime}$ bromines. We therefore come to a conclusion that the bromination of OH-PBDEs plays a crucial role in the complexations with BSA. These interesting findings provide sufficient stimulus for us to further investigate the interactions between BSA and OH-PBDEs with even higher degree of bromination, e.g., hydroxylated nonabromodiphenyl ethers (OH-nonaBDEs), which are not commercially available yet. This will be the subject of our future dedicated study.

\subsection{Investigation of ligand-induced conformational changes by IM-MS}

Aiming to contribute a better understanding of the interaction behavior between OH-PBDEs and BSA, IM-MS approach was employed in the present work to get an insight into the possible ligand-mediated conformational changes in BSA occurring upon the binding of OH-PBDEs. IM-MS allows the evaluation of gas-phase drifting trajectory of protein complex ions, which can be related to overall shapes of the noncovalent protein assembly, and thus used to monitor changes in structure. Preliminary experiments for optimizing ion mobility conditions were carried out by infusing the BSA solution into the ESI interface of the spectrometer by use of an integrated syringe pump. Three parameters, i.e., IM-MS gas flow rate, traveling wave velocity and traveling wave height, which are directly related to the effects on ion mobility separation, were finely tuned. Successively holding two of the three variables constant, the third was adjusted until the optimal ion mobility separation was obtained under the circumstance. The parameter of IM-MS gas flow rate was found to show a great impact on ion mobility separation. By varying the IM-MS gas flow rate from 5 to $40 \mathrm{~mL} / \mathrm{min}$, a flow rate of $15 \mathrm{~mL} / \mathrm{min}$ appropriately allowed the analyte ions to move across the ion mobility drift tube during one pulse cycle. It was observed that increased traveling wave velocity would widen the drift time distribution profile, while increased traveling wave height would narrow it. A $300 \mathrm{~m} / \mathrm{s}$ traveling wave at the amplitude of $8.0 \mathrm{~V}$ gave optimum ion mobility separation in the trial.

Under exactly the same instrumental conditions, the untreated BSA sample as well as BSA individually incubated with $4^{\prime}-\mathrm{OH}-\mathrm{BDE}$ 201, 4-OH-BDE-187 and 6-OH-BDE-180, which exhibited binding potency to BSA as evidenced in the ESI-MS protocol, was subjected to the IM-MS analysis. The rapid ion mobility separation was conducted during a very short period of $25.64 \mathrm{~ms}$. A fast scanning TOF-MS enabled plenty of information to be acquired and recorded during the entire procedure. The drift time versus $m / z$ plot shown in Fig. 4a displays the drift time distribution of different $m / z$ species of the ligand-free BSA. The band color reflects the signal intensity of the ions, with white representing the highest intensity and black the lowest intensity. As a result of multiple charging phenomenon associated with ESI, serial BSA ions with various charge states from $15+$ to $18+$ were broadly dispersed through the nitrogen IM-MS gas with drift times ranging from 4.81 to $7.12 \mathrm{~ms}$. The drift times of BSA are inversely related to the electric charges carried. The signal at shorter drift time and lower $m / z$ can be assigned to charge state $18+$, while the signal at longer drift time and higher $m / z$ corresponds to charge state $15+$. During the IM-MS analysis, ions pass through the neutral buffer gas under the influence of a weak electric field with drift times being dependent on their mobility values. Ions having higher electric charges will experience greater separation field strengths and migrate through the ion mobility region within a shorter period of time than those with lower charges. The charge state $18+$ with the highest mobility drifts most rapidly through the mobility region, emerging in the left-hand part of the plot. The charge state 15+ moves toward the end due to the lowest mobility, showing up in the right-hand part. As indicated in the representative drift time versus $m / z$ plot of the incubation mixture of BSA and 4'-OH-BDE-201 (Fig. 4b), several well-defined signals, corresponding to the OH-PBDEs/BSA complex ions with electric charges from $14+$ to $17+$, linearly scatter in the plot. For each charge-state species, the formation of noncovalent complex is substantiated by the increments of one and two molecules of OH-PBDEs in the observed $m / z$ distribution. Examination of the experimental ion mobility data allows us to immediately identify that the relative abundance of a set of signals shifts toward higher $\mathrm{m} / \mathrm{z}$ upon the binding of $\mathrm{OH}-$ PBDEs to BSA. For instance, the signal for charge state $14+$ is almost 
not visible in Fig. 4a, but is clearly displayed in Fig. 4b; the signal intensity corresponding to charge state +18 is quite apparent as shown in Fig. 4a, but nearly disappears in Fig. 4b. This visualized migration of signals reflects a change in surface protonation propensity of BSA, which is consistent with our observation in the ESI-MS experiment, demonstrating that the structural information of the noncovalent complex is largely conserved during the gasphase ion mobility separation. As a result, the IM-MS approach

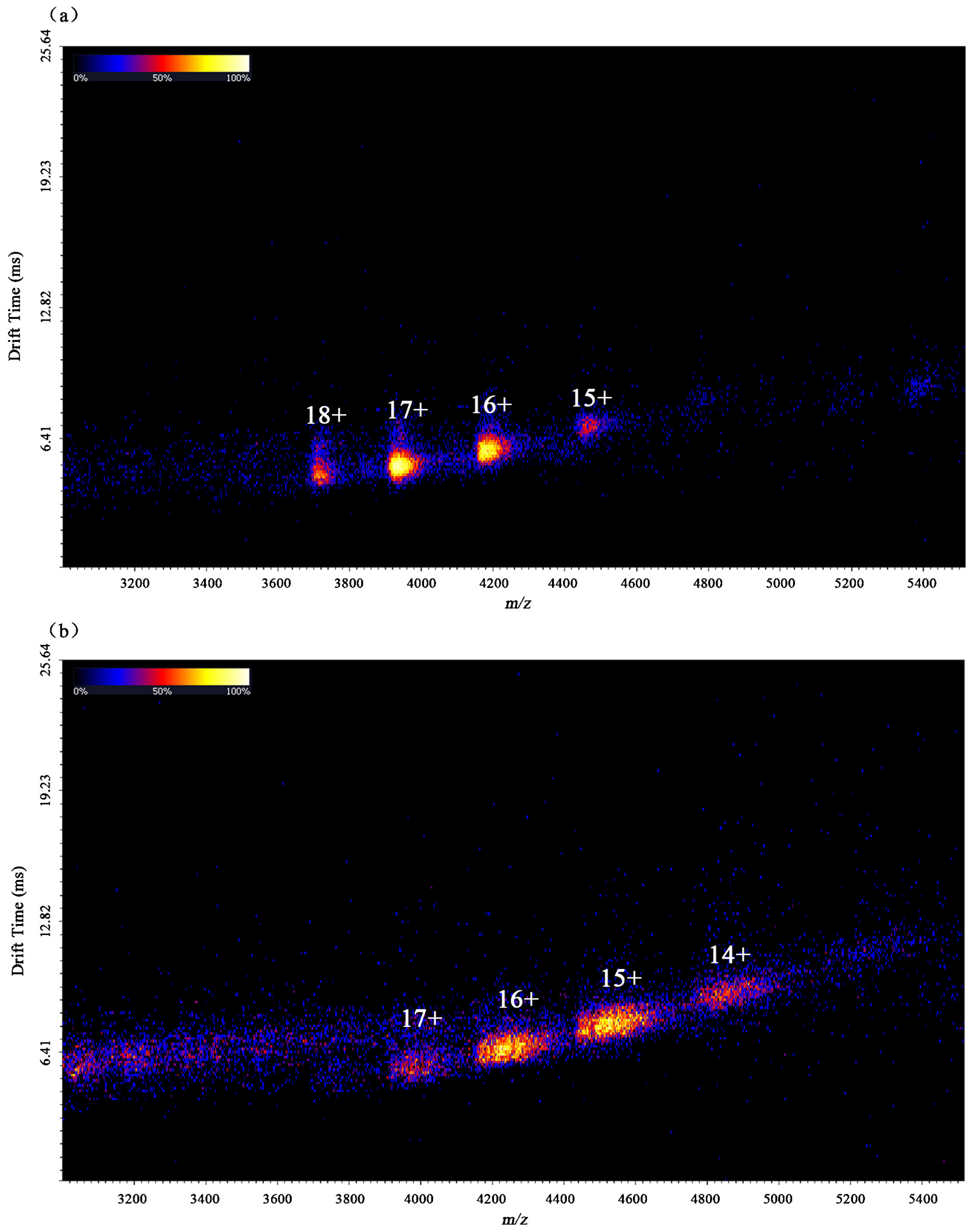

Fig. 4. The drift time versus $m / z$ plots of untreated BSA (a) and BSA treated with $4^{\prime}$-OH-BDE-201 (b) with identical instrumental parameters. 


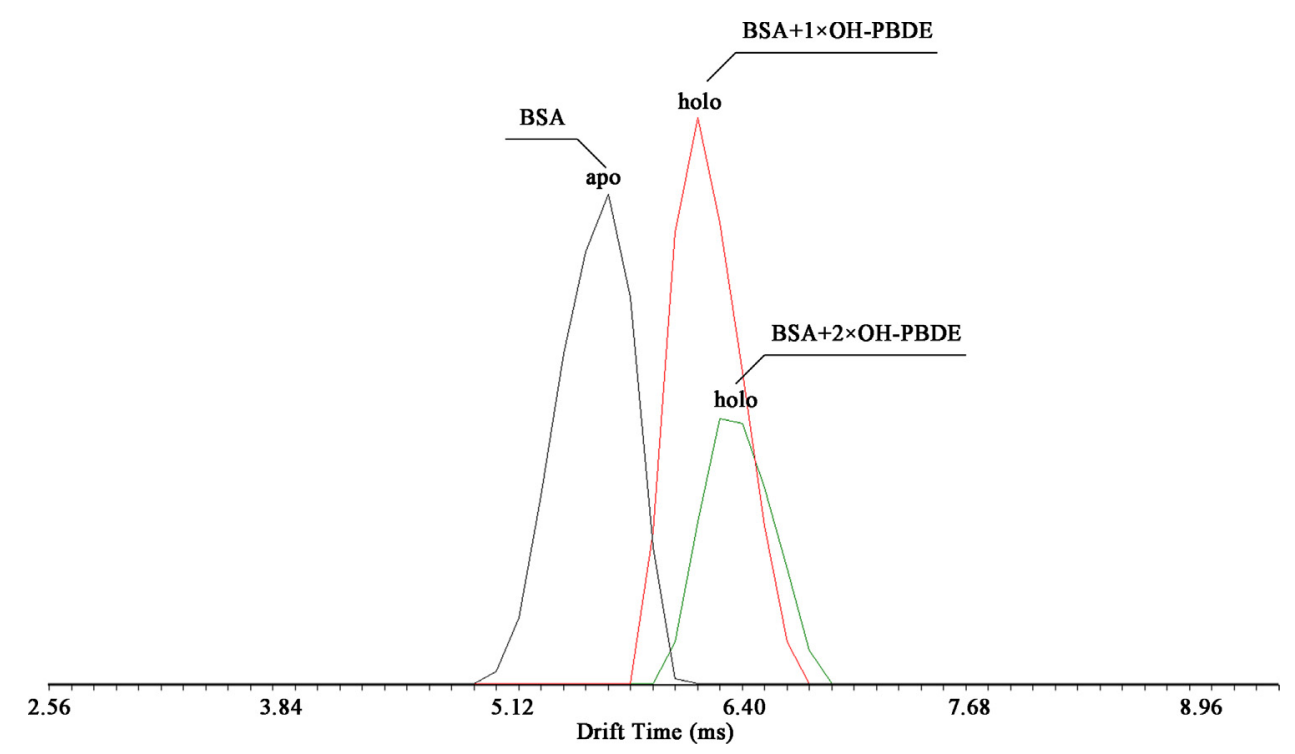

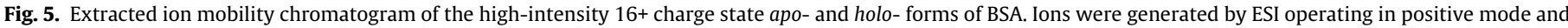
then subjected to an ion mobility separation with nitrogen mobility gas flow rate of $15 \mathrm{~mL} / \mathrm{min}$ and a $300 \mathrm{~m} / \mathrm{s}$ traveling wave at the amplitude of $8.0 \mathrm{~V}$.

provides further evidence for the complexation of BSA with $\mathrm{OH}-$ PBDEs.

Over the past decade, IM-MS has become a useful technique for studying the shape and conformation of proteins due to the direct structural information available from the ion mobility dimension. Ions of the proteins with compact conformation will pass through the drift region more rapidly due to higher mobility, while ions of the proteins with extended conformation will experience a greater number of collisions with the background inert gas and hence have lower mobility and traverse across the region more slowly. Therefore, allosteric conformational transitions of proteins, which will exhibit different drifting trajectories, can be characterized based on varying drift times. In this study, Fig. 4a showed clearly that there is only one species of protonated BSA, that is, there is only one conformer shown for BSA with some five charge states. With strictly identical ion mobility parameters, the drift times for multiple charge states of apo- form of BSA before (Fig. 4a) and after (Fig. 4b) treatment with 4'-OH-BDE-201 remain constant, indicating excellent reproducibility of drift times between analyses. As can be seen in the reconstructed ion mobility chromatogram for BSA treated with 4'-OH-BDE-201 (Fig. 5), there are subtle drift time differences between apo- and holo- forms of BSA. This $8 \%$ shift of the measured drift times upon OH-PBDEs binding may partly be ascribed to the attachment of one and two molecules of $4^{\prime}-\mathrm{OH}-\mathrm{BDE}-$ 201 , which lead to a minor delay in drifting trajectory. It is difficult to make confirmative judgment that OH-PBDEs may stimulate conformational alterations to BSA based on the current experimental results, and this may need further investigation in future.

\section{Conclusions}

The noncovalent complexations between BSA and 24 OH-PBDE compounds with different level of bromination and various hydroxylation positions have been studied using ESI-MS. By virtue of careful optimization of the instrumental settings, the experimental results prove that intact noncovalent $\mathrm{OH}$-PBDEs/BSA complexes can be well preserved and transferred from solution phase to gas phase. Among the $\mathrm{OH}-\mathrm{PBDE}$ congeners investigated, one $\mathrm{OH}-$ octaBDE (4'-OH-BDE-201) and two OH-heptaBDEs (4-OH-BDE-187 and 6-OH-BDE-180) have been validated to show binding potency to BSA with $1: 1$ and $2: 1$ stoichiometries. The corresponding dissociation constants of the OH-PBDEs/BSA complexes were obtained based on titration curve data fitting. The binding affinity of OH-PBDEs to BSA is found to be dependent on their chemical functionalities, including degree of bromination, positions of hydroxyl and bromine moieties. Traveling wave IM-MS experiment further confirmed the complexations of BSA with OH-PBDEs. These observations imply that some $\mathrm{OH}-\mathrm{PBDEs}$ with high level of bromination possess competitive binding capability with serum albumin, hence potential displacement of thyroid hormones from serum albumin may occur, leading to disruption of thyroid functions.

\section{Acknowledgements}

The authors are grateful to Professor Raymond E. March at Trent University, and Dr. Hai-Wei Xi, Dr. Peter J. Lee, Dr. Xi Chen and Dr. Xiao-Fei Jia at Waters Corporation for their discussion on data interpretation. This work was financially supported by the National Natural Science Foundation of China (21307123), the National Basic Research Program of China (2011CB936001), the Science Research Program of Chinese Academy of Inspection and Quarantine (2012JK021), and the Science Research Program of General Administration of Quality Supervision, Inspection and Quarantine of China (2013IK024).

\section{Appendix A. Supplementary data}

Supplementary data associated with this article can be found, in the online version, at http://dx.doi.org/10.1016/j.ijms.2013.10.007.

\section{References}

[1] T. Hyötyläinen, K. Hartonen, Determination of brominated flame retardants in environmental samples, Trends Anal. Chem. 21 (2002) 13-29.

[2] J.L. Domingo, Polybrominated diphenyl ethers in food and human dietary exposure: a review of the recent scientific literature, Food Chem. Toxicol. 50 (2012) 238-249.

[3] I.A. Meerts, J.J. van Zanden, E.A. Luijks, I. van Leeuwen-Bol, G. Marsh, E. Jakobsson, A. Bergman, A. Brouwer, Potent competitive interactions of some brominated flame retardants and related compounds with human transthyretin in vitro, Toxicol. Sci. 56 (2000) 95-104.

[4] S. Kitamura, S. Shinohara, E. Iwase, K. Sugihara, N. Uramaru, H. Shigematsu, N. Fujimoto, S. Ohta, Affinity for thyroid hormone and estrogen receptors of hydroxylated polybrominated diphenyl ethers, J. Health Sci. 54 (2008) 607-614. 
[5] M.M. Dingemans, A. de Groot, R.G. van Kleef, Å. Bergman, M. van den Berg, H.P. Vijverberg, R.H. Westerink, Hydroxylation increases the neurotoxic potential of BDE-47 to affect exocytosis and calcium homeostasis in PC12 cells, Environ. Health Perspect. 116 (2008) 637-643.

[6] R. Song, T.L. Duarte, G.M. Almeida, P.B. Farmer, M.S. Cooke, W. Zhang, G. Sheng, J. Fu, G.D. Jones, Cytotoxicity and gene expression profiling of two hydroxylated polybrominated diphenyl ethers in human H295R adrenocortical carcinoma Cells, Toxicol. Lett. 185 (2009) 23-31.

[7] I.A. Meerts, R.J. Letcher, S. Hoving, G. Marsh, Å. Bergman, J.G. Lemmen, B. van der Burg, A. Brouwer, In vitro estrogenicity of polybrominated diphenyl ethers, hydroxylated PBDEs, and polybrominated bisphenol A compounds, Environ. Health Perspect. 109 (2001) 399-407.

[8] R.F. Cantón, D.E. Scholten, G. Marsh, P.C. de Jong, M. van den Berg, Inhibition of human placental aromatase activity by hydroxylated polybrominated diphenyl ethers (OH-PBDEs), Toxicol. Appl. Pharmacol. 227 (2008) 68-75.

[9] C.A. de Wit, D. Herzke, K. Vorkamp, Brominated flame retardants in the Arctic environment-Trends and new candidates, Sci. Total Environ. 408 (2010) 2885-2918.

[10] D. Ueno, C. Darling, M. Alaee, G. Pacepavicius, C. Teixeira, L. Campbell, R.J. Letcher, Å. Bergman, G. Marsh, D. Muir, Hydroxylated polybrominated diphenyl ethers (OH-PBDEs) in the abiotic environment: surface water and precipitation from Ontario, Canada, Environ. Sci. Technol. 42 (2008) 1657-1664.

[11] Y. Kato, S. Okada, K. Atobe, T. Endo, F. Matsubara, T. Oguma, K. Haraguchi, Simultaneous determination by APCI-LC/MS/MS of hydroxylated and methoxylated polybrominated diphenyl ethers found in marine biota, Anal. Chem. 81 (2009) 5942-5948

[12] S. Lacorte, M.G. Ikonomou, M. Fischer, A comprehensive gas chromatography coupled to high resolution mass spectrometry based method for the determination of polybrominated diphenyl ethers and their hydroxylated and methoxylated metabolites in environmental samples, J. Chromatogr. A 1217 (2010) 337-347

[13] M. Houde, G. Pacepavicius, C. Darling, P.A. Fair, M. Alaee, G.D. Bossart, K.R. Solomon, R.J. Letcher, Å. Bergman, G. Marsh, D.C. Muir, Polybrominated diphenyl ethers and their hydroxylated analogs in plasma of bottlenose dolphins (tursiops truncatus) from the United States east coast, Environ. Toxicol. Chem. 28 (2009) 2061-2068.

[14] A. Malmvärn, Y. Zebühr, L. Kautsky, Å. Bergman, L. Asplund, Hydroxylated and methoxylated polybrominated diphenyl ethers and polybrominated dibenzop-dioxins in red alga and cyanobacteria living in the Baltic Sea, Chemosphere 72 (2008) 910-916.

[15] B.C. Kelly, M.G. Ikonomou, J.D. Blair, F.A. Gobas, Hydroxylated and methoxylated polybrominated diphenyl ethers in a Canadian arctic marine food web, Environ. Sci. Technol. 42 (2008) 7069-7077.

[16] Y. Wan, K. Choi, S. Kim, K. Ji, H. Chang, S. Wiseman, P.D. Jones, J.S. Khim, S. Park, J. Park, M.H. Lam, J.P. Giesy, Hydroxylated polybrominated diphenyl ethers and bisphenol A in pregnant women and their matching fetuses: placental transfer and potential risks, Environ. Sci. Technol. 44 (2010) 5233-5239.

[17] X. Qiu, R.M. Bigsby, R.A. Hites, Hydroxylated metabolites of polybrominated diphenyl ethers in human blood samples from the United States, Environ. Health Perspect. 117 (2009) 93-98.

[18] Z. Yu, K. Zheng, G. Ren, Y. Zheng, S. Ma, P. Peng, M. Wu, G. Sheng, J. Fu, Identification of hydroxylated octa- and nona-bromodiphenyl ethers in human serum from electronic waste dismantling workers, Environ. Sci. Technol. 44 (2010) 3979-3985

[19] M. Athanasiadou, S.N. Cuadra, G. Marsh, Å. Bergman, K. Jakobsson, Polybrominated diphenyl ethers (PBDEs) and bioaccumulative hydroxylated PBDE metabolites in young humans from Managua, Nicaragua, Environ. Health Perspect. 116 (2008) 400-408.

[20] A.R. Zota, J.S. Park, Y. Wang, M. Petreas, R.T. Zoeller, T.J. Woodruff, Polybrominated diphenyl ethers, hydroxylated polybrominated diphenyl ethers, and measures of thyroid function in second trimester pregnant women in California, Environ. Sci. Technol. 45 (2011) 7896-7905

[21] G. Ren, Z. Yu, S. Ma, K. Zheng, Y. Wang, M. Wu, G. Sheng, J. Fu, Determination of polybrominated diphenyl ethers and their methoxylated and hydroxylated metabolites in human serum from electronic waste dismantling worker, Anal. Methods 3 (2011) 408-413

[22] A. Sjödin, R.S. Jones, J.-F. Focant, C. Lapeza, R.Y. Wang, E.E. 3rd McGahee, Y. Zhang, W.E. Turner, B. Slazyk, L.L. Needham, D.G. Patterson Jr., Retrospective time-trend study of polybrominated diphenyl ether and polybrominated and polychlorinated biphenyl levels in human serum from the United States, Environ. Health Perspect. 112 (2004) 654-658.

[23] R.A. Hites, Polybrominated diphenyl ethers in the environment and in people: a meta-analysis of concentrations, Environ. Sci. Technol. 38 (2004) 945-956.

[24] P.O. Darnerud, M. Aune, L. Larsson, S. Hallgren, Plasma, PBDE and thyroxine levels in rats exposed to bromkal or BDE-47, Chemosphere 67 (2007) S386-S392.

[25] T.E. Stoker, S.C. Laws, K.M. Crofton, J.M. Hedge, J.M. Ferrell, R.L. Cooper, Assessment of DE-71, a commercial polybrominated diphenyl ethers (PBDE) mixture, in the EDSP male and female pubertal protocols, Toxicol. Sci. 78 (2004) $144-155$.

[26] T. Zhou, M.M. Taylor, M.J. DeVito, K.M. Crofton, Developmental exposure to brominated diphenyl ethers results in thyroid hormone disruption, Toxicol. Sci. 66 (2002) 105-116

[27] P.M. Yen, Physiological and molecular basis of thyroid hormone action, Physiol. Rev. 81 (2001) 1097-1142.

[28] J. Bernal, A. Guadaño-Ferraz, B. Morte, Perspectives in the study of thyroid hormone action on brain development and function, Thyroid 13 (2003) 1005-1012.
[29] C.B. Harvey, G.R. Williams, Mechanism of thyroid hormone action, Thyroid 12 (2002) 441-446.

[30] J.E. Silva, The multiple contributions of thyroid hormone to heat production, J. Clin. Invest. 108 (2001) 35-37.

[31] K.M. Crofton, Thyroid disrupting chemicals: mechanisms and mixtures, Int. J. Androl. 31 (2008) 209-223.

[32] S. Hallgren, P.O. Darnerud, Polybrominated diphenyl ethers (PBDEs), polychlorinated biphenyls (PCBs) and chlorinated paraffins (CPs) in rats-testing interactions and mechanisms for thyroid hormone effects, Toxicology 177 (2002) 227-243.

[33] A. Brouwer, D.C. Morse, M.C. Lans, A.G. Schuur, A.J. Murk, E. Klasson-Wehler, Å Bergman, T.J. Visser, Interactions of persistent environmental organohalogens with the thyroid hormone system: mechanisms and possible consequences for animal and human health, Toxicol. Ind. Health 14 (1998) 59-84.

[34] T.A. McDonald, A perspecitve on the potential health risks of PBDEs, Chemosphere 46 (2002) 745-755.

[35] J. Legler, A. Brouwer, Are brominated flame retardants endocrine disruptors? Environ. Int. 29 (2003) 879-885.

[36] J. Cao, Y. Lin, L.H. Guo, A.Q. Zhang, Y. Wei, Y. Yang, Structure-based investigation on the binding interaction of hydroxylated polybrominated diphenyl ethers with thyroxine transport proteins, Toxicology 277 (2010) 20-28.

[37] G.R. Marchesini, A. Meimaridou, W. Haasnoot, E. Meulenberg, F. Albertus, M. Mizuguchi, M. Takeuchi, H. Irth, A.J. Murk, Biosensor discovery of thyroxine transport disrupting chemicals, Toxicol. Appl. Pharmacol. 232 (2008) 150-160.

[38] W. Yang, S. Shen, L. Mu, H. Yu, Structure-activity relationship study on the binding of PBDEs with thyroxine transport proteins, Environ. Toxicol. Chem. 30 (2011) 2431-2439.

[39] X.M. He, D.C. Carter, Atomic structure and chemistry of human serum albumin, Nature 358 (1992) 209-215.

[40] D.C. Carter, J.X. Ho, Structure of serum albumin, Adv. Protein Chem. 45 (1994) $153-203$.

[41] G. Sudlow, DJ. Birkett, D.N. Wade, The characterization of two specific drug binding sites on human serum albumin, Mol. Pharmacol. 11 (1975) 824-832.

[42] T. Peters Jr., Serum Albumin, Adv. Protein Chem. 37 (1985) 161-245.

[43] L.A. MacManus-Spencer, M.L. Tse, P.C. Hebert, H.N. Bischel, R.G. Luthy, Binding of perfluorocarboxylates to serum albumin: a comparison of analytical methods, Anal. Chem. 82 (2010) 974-981.

[44] M. Mann, C.K. Meng, J.B. Fenn, Interpreting mass spectra of multiply charged ions, Anal. Chem. 61 (1989) 1702-1708.

[45] J.B. Fenn, M. Mann, C.K. Meng, S.F. Wong, C.M. Whitehouse, Electrospray ionization for mass spectrometry of large biomolecules, Science 246 (1989) 64-71.

[46] C.A. Schalley, A. Springer, Mass Spectrometry and Gas-Phase Chemistry of NonCovalent Complexes, Wiley, New Jersey, 2009.

[47] J.A. Loo, Studying noncovalent protein complexes by electrospray ionization mass spectrometry, Mass Spectrom. Rev. 16 (1997) 1-23.

[48] A.J. Heck, R.H. van den Heuvel, Investigation of intact protein complexes by mass spectrometry, Mass Spectrom. Rev. 23 (2004) 368-389.

[49] M. Sharon, C.V. Robinson, The role of mass spectrometry in structure elucidation of dynamic protein complexes, Annu. Rev. Biochem. 76 (2007) 167-193.

[50] V.L. Morton, P.G. Stockley, N.J. Stonehouse, A.E. Ashcroft, Insights into virus capsid assembly from non-covalent mass spectrometry, Mass Spectrom. Rev. 27 (2008) 575-595.

[51] D.E. Koshland, Application of a theory of enzyme specificity to protein synthesis, Proc. Natl. Acad. Sci. U.S.A. 44 (1958) 98-104.

[52] C. Atmanene, S. Petiot-Bécard, D. Zeyer, A. van Dorsselaer, V. Vivat Hannah, S. Sanglier-Cianférani, Exploring key parameters to detect subtle ligand-induced protein conformational changes using travelling wave ion mobility mass spectrometry, Anal. Chem. 84 (2012) 4703-4710.

[53] B.T. Ruotolo, J.L. Benesch, A.M. Sandercock, S.J. Hyung, C.V. Robinson, Ion mobility-mass spectrometry analysis of large protein complexes, Nat. Protoc. 3 (2008) 1139-1152.

[54] E. van Duijn, A. Barendregt, S. Synowsky, C. Versluis, A.J. Heck, Chaperonin complexes monitored by ion mobility mass spectrometry, J. Am. Chem. Soc. 131 (2009) 1452-1459.

[55] G.A. Eiceman, Z. Karpas, Ion Mobility Spectrometry, 2nd ed., CRC Press, Boca Raton, 2005

[56] C. Uetrecht, R.J. Rose, E. van Duijn, K. Lorenzen, A.J. Heck, Ion mobility mass spectrometry of proteins and protein assemblies, Chem. Soc. Rev. 39 (2010) 1633-1655.

[57] D.P. Smith, T.W. Knapman, I. Campuzano, R.W. Malham, J.T. Berryman, S.E. Radford, A.E. Ashcroft, Deciphering drift time measurements from travelling wave ion mobility spectrometry-mass spectrometry studies, Eur. J. Mass Spectrom. 15 (2009) 113-130

[58] C.A. Scarff, K. Thalassinos, G.R. Hilton, JH Scrivens, Travelling wave ion mobility mass spectrometry studies of protein structure: biological significance and comparison with X-ray crystallography and nuclear magnetic resonance spectroscopy measurements, Rapid Commun. Mass Spectrom. 22 (2008) 3297-3304.

[59] K. Thalassinos, M. Grabenauer, S.E. Slade, G.R. Hilton, M.T. Bowers, J.H. Scrivens, Characterization of phosphorylated peptides using travelling wave-based and drift cell ion mobility mass spectrometry, Anal Chem. 81 (2009) 248-254.

[60] J.A. Leary, M.R. Schenauer, R. Stefanescu, A. Andaya, B.T. Ruotolo, C.V. Robinson, K. Thalassinos, J.H. Scrivens, M. Sokabe, J.W. Hershey, Methodology for measuring conformation of solvent-disrupted protein subunits using T-WAVE ion mobility MS: an investigation into eukaryotic initiation factors, J. Am. Soc Mass Spectrom. 20 (2009) 1699-1706. 
[61] S.D. Pringle, K. Giles, J.L. Wildgoose, J.P. Williams, S.E. Slade, K. Thalassinos, R.H Bateman, M.T. Bowers, J.H. Scrivens, An investigation of the mobility separation of some peptide and protein ions using a new hybrid quadrupole/travelling wave IMS/oa-ToF instrument, Int. J. Mass spectrom. 261 (2007) 1-12.

[62] V.G. Giganti, S. Kundoor, W.A. Best, L.A. Angel, Ion mobility-mass spectrometry study of folded ubiquitin conformers induced by treatment with cis-[Pd(en)( $\left.\left.\mathrm{H}_{2} \mathrm{O}\right)_{2}\right]^{2+}$, J. Am. Soc. Mass Spectrom. 22 (2011) 300-309.

[63] Y. Seo, M.R. Schenauer, J.A. Leary, Biologically relevant metal-cation binding induces conformational changes in heparin oligosaccharides as measured by ion mobility mass spectrometry, Int. J. Mass spectrom. 303 (2011) 191-198.

[64] C. Atmanene, D. Chaix, Y. Bessin, N. Declerck, A.V. Dorsselaer, S. SanglierCianferani, Combination of noncovalent mass spectrometry and travelling wave ion mobility spectrometry reveals sugar-induced conformational changes of central glycolytic genes repressor/DNA complex, Anal. Chem. 82 (2010) 3597-3605

[65] Method 1614 brominated diphenyl ethers in water soil, sediment and tissue by 14 HRGC/HRMS, August 2007, United States Environmental Protection Agency.
[66] W. Davidson, J.L. Hopkins, D.D. Jeanfavre, K.L. Barney, T.A. Kelly, C.A Grygon, Characterization of the allosteric inhibition of a protein-protein interaction by mass spectrometry, J. Am. Soc. Mass Spectrom. 14 (2003) 8-13.

[67] G. Zhang, N. Zhao, X. Hu, J. Tian, Interaction of alpinetin with bovine serum albumin: probing of the mechanism and binding site by spectroscopic methods, Spectrochim. Acta. A. Mol. Biomol. Spectrosc. 76 (2010) 410-417.

[68] J.J. Vallner, Binding of drugs by albumin and plasma protein, J. Pharm. Sci. 66 (1977) 447-465.

[69] D.J. Winzor, W.H. Sawyer, Quantitative Characterization of Ligand Binding, Wiley, New York, 1995.

[70] K.A. Sannes-Lowery, R.H. Griffey, S.A. Hofstadler, Measuring dissociation constants of RNA and aminoglycoside antibiotics by electrospray ionization mass spectrometry, Anal. Biochem. 280 (2000) 264-271.

[71] D.C. Carter, J.X. Ho, Structure of Serum Albumin, Adv. Protein Chem. 45 (1994) 177-203. 